\title{
Coronary artery disease in a rural population of Bangladesh: is dyslipidemia or adiposity a significant risk?
}

\author{
Sajal Krishna Banerjee', Chaudhury Meshkat Ahmed ${ }^{1}$, Mir Masudur Rhaman' \\ Mohammad Mainul Hasan Chowdhury ${ }^{3}$ and M. Abu Sayeed ${ }^{2}$ \\ ${ }^{I}$ Department of Cardiology, Bangabandhu Sheikh Mujib Medical University (BSMMU), Dhaka \\ ${ }^{2}$ Department of Community Medicine, Ibrahim Medical College (IMC), Dhaka \\ ${ }^{3}$ Department of Internal Medicine, BSMMU, Dhaka
}

\begin{abstract}
Background and Aims: The prevalence of cardiovascular diseases (CVD) are on the increase worldwide and more in the developing countries. Coronary artery disease (CAD) constitutes the major brunt of CVD. Despite the increasing morbidity and mortality, Bangladesh has a few published data on CAD in rural population. This study addressed the prevalence of CAD and its risk factors in rural population of Bangladesh.

Study methods: Sixteen villages were purposively selected in a rural area. A population census was conducted in the selected area. The census yielded eligible participants, who reached at least eighteen years of age. Those who willingly consented to participate were enlisted. Each participant was interviewed regarding CAD risk (age, sex, social class, occupation, illness, family history). Anthropometry (height, weight, waist- and hip-girth) was recorded. Resting blood pressure (BP) was measured. Blood sample was collected for fasting blood glucose (FBG), total cholesterol (Chol), triglycerides (Tg), low density lipoproteins (LDL), very low density lipoproteins (VLDL) and high density (HDL). All participants having FBG $>5.5 \mathrm{mmol} / 1$ or systolic (SBP) $\geq 135$ or diastolic $\mathrm{BP}$ (DBP) $\geq 85 \mathrm{mmHg}$ underwent electrocardiography (ECG). A team of cardiologists selected and accomplished exercise tolerance test (ETT) and echocardiography (Echo).

Results: The prevalence of CAD was $4.5 \%$ (95\% CI: 3.85 - 5.15). Compared with the female (3.5\%, CI, $2.76-4.24)$ the male participants had significantly higher prevalence of CAD $(6.0 \%, \mathrm{CI}, 4.83-7.13)$. Comparison of characteristics between participants with and without CAD showed that age, SBP, DBP and FBG were significantly higher in CAD group. Bivariate analysis showed that age, sex, social class, glycemic status, metabolic syndrome (MetS) and smoking were significantly related to CAD. Stepwise logistic regression proved only male sex, rich social class, hypertension and diabetes had independent risk of CAD; whereas, age, obesity and dyslipidemia were proved not significant.

Conclusions: The study concludes that the prevalence of CAD in a Bangladeshi rural population is comparable to other developed countries. The male sex, rich social class, hypertension and diabetes were proved to have excess risk of CAD. Neither obesity nor dyslipidemia were found significant for CAD. The younger people had similar risk as the aged ones, which necessitate primordial and primary prevention of CAD. Further study may be undertaken, which should include and consider physical activity and diet; and if possible, Creactive protein, Vitamin D and homocysteine level.
\end{abstract}

IMC J Med Sci 2017; 11(2): 61-69

Address for Correspondence:

Prof. M. Abu Sayeed, Department of Community Medicine, Ibrahim Medical College, 122 Kazi Nazrul Islam Avenue Shahbag, Dhaka-1000.email: sayeed@imc.ac.bd 


\section{Introduction}

The burden of atherosclerotic diseases is progressively increasing [1]. The projected deaths from cardiovascular diseases (CVD) in 2030 is estimated to reach 23.6 million $(34.8 \%)$ of the world population. Thus, it is clear that the clinical and socioeconomic impact of CVD is considerable. The World Health Organization (WHO) statistics of 2004 showed that CVD represents the number one cause of death worldwide, approximating $30 \%$ of total mortality [1]. Considering these facts, WHO and its partners launched a new initiative "Global Hearts" on 22 September, 2016 [2]. The initiative aimed to minimize the global threat of cardiovascular disease, the world's leading cause of death.

The questions remained still unanswered how to minimize the global threat and how to prevent morbidity and mortality of CVD. Though multiple risk factors like adiposity and metabolic disorders have been identified, these are found inconsistent in different studies. For example, some studies observed that obesity is a significant risk for coronary artery disease (CAD) [3,4]. In contrast, some studies reported that non-obese people also had risk for cardiovascular deaths [5] and different populations with an obesity paradox by BMI showed different risk [6].

As regards Bangladesh, there are few published data that estimated the magnitude of CVD and its related morbidity or mortality. Some investigators showed several known risks (obesity, smoking, lipids) prevalent amongst the south Asians (India, Pakistan, Bangladesh, Sri Lanka and Nepal) [8]. But these risk factors have not been studied in relation to $\mathrm{CAD}$, and no study investigated which of the risks and how much of it significantly related to CAD. This study aimed to determine the prevalence of CAD in a rural community of Bangladesh. Additionally, the study attempted to investigate some known risk factors attributed to CAD.

\section{Study design}

The study proposal was approved by the Ethical Review Committee of Bangladesh Diabetic Samity (BADAS).
According to protocol, sixteen villages were purposively selected in a rural area - located northeast of Dhaka city and inhabited mostly by the population involved in agrarian occupation. The area is connected to Dhaka city by $110 \mathrm{~km}$ of paved and $10 \mathrm{~km}$ of non-paved road. A census was conducted in these villages. The census included socio-demographic information (age, sex, education, occupation and family income). It also included family history of non-communicable diseases (NCD). Individual equal to or greater than 18 years of age was considered eligible. The eligible participants ( $\geq 18$ years) were randomized. The eligible participants were detailed (objectives, methods) about the study. Those who consented to volunteer the study were invited for stepwise investigations.

\section{Step 1}

Interviewing - In the morning, the participant was interviewed about occupation, education, income, illness (present or past) and medication. Interviewing on family-history included diabetes, hypertension (HTN), stroke, coronary heart diseases (CHD), peripheral vascular disease (PVD), foot-ulcer and leg amputation. The information was recorded based on medical reports (investigation, prescription) and verbal autopsy.

Anthropometric and blood pressure (BP) measurements: Height, weight, waist- and hip-girth were measured. Body mass index $(\mathrm{BMI}=$ weight in $\mathrm{kg} /$ height in met sq.), waist-to-hip ratio (WHR = waist $/$ hip) and waist-to-height ratio (WHtR $=$ Waist / height) were calculated. Blood pressure was taken after 10 minutes of rest.

\section{Step 2}

Collection of blood sample: Five milliliter of fasting blood sample was collected aseptically for estimation of fasting blood glucose (FBG mmol/l) and lipids (total cholesterol, triglycerides, lowdensity lipoprotein, high-density and very high density lipoproteins). While collecting blood sample a drop of blood was taken on a finger strip for rapid assessment of FBG. The participants, who showed SBP / DBP $\geq 135 / 85 \mathrm{mmHg}$ and/ or $\mathrm{FBG} \geq 5.6 \mathrm{mmol} / \mathrm{l}$ were referred to electrocardiography (ECG) tracing. 
Step 3

A team of cardiologists examined all ECG tracings. According to the need of the cardiologists the ECG was repeated and for confirmation the participants were referred to the Department of Cardiology, Bangabandhu Sheikh Mujib Medical University (BSMMU) in Dhaka for ehocardiography (Echo) and exercise tolerance tests (ETT). Diagnosis of CAD was based on - a) history of angina plus ischemic change in ECG either at rest or on stress; b) post-myocardial infarction (MI) with Q-wave MI or non-QMI.

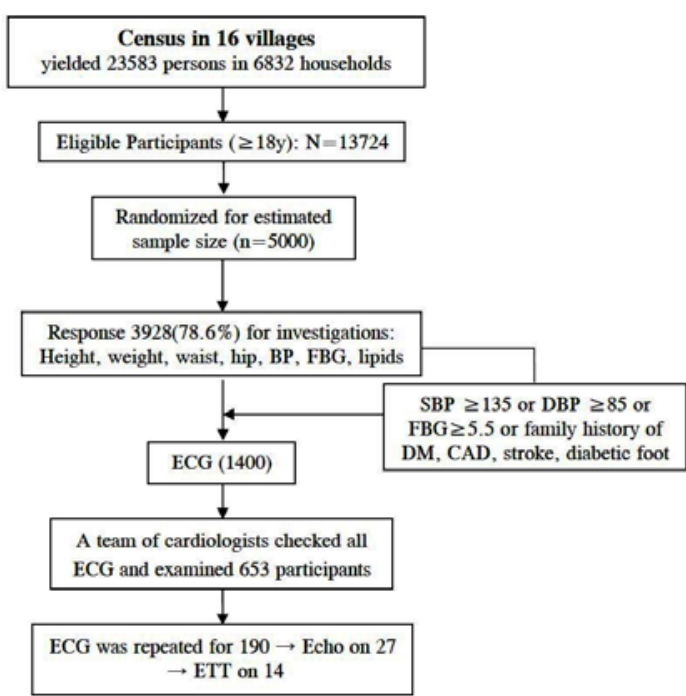

Fig-1: Algorithm of the study

Note: $S B P, D B P$ - systolic, diastolic blood pressure in $\mathrm{mmHg}$; $F B G$ - fasting blood glucose in mmol/l; CAD - coronary artery disease; ECG - electrocardiography; Echo - echocardiography; ETT - exercise tolerance test;

Statistical analyses: Prevalence rates were given in percentages. Student's t-tests were used for comparison of variables between groups (men vs. women, non-CAD vs.CAD) with mean and standard deviation (Mean $\pm \mathrm{SD}$ ). To find out associations between different qualitative variables we used Chi sq $\left(\chi^{2}\right)$ test. The quantitative variables were transformed into quartiles $(Q)$ for determining the trend of CAD prevalence from lowest (Q1) to the highest quartile (Q4). Stepwise logistic regression analysis quantified the risk variables as independent and CAD as a dependent variable. The findings were expressed as Odds ratio (OR) with $95 \%$ confidence interval (CI). In each test the level of significance was accepted if $p<0.05$. For all these analyses SPSS/PC + was used.

\section{Results}

As mentioned, the census in 16 villages yielded 22863 persons of all ages in 6823 households (Figure 1). The observed age groups were: $4.6 \%$, $37.1 \%$ and $58.3 \%$ in $<2,2-17$ and $\geq 18$ years of age, respectively (Table 1 ). Of the eligible group for CAD ( $\geq 18 \mathrm{y}: \mathrm{n}=13724$ ), an estimated sample of 5000 were randomly selected for investigations (Figure 1). Of them, 3928 (m / f = $1590 / 2338$ ) volunteered. Overall, the response rate was $78.6 \%$.

Table-1: Distribution of age and sex according to census

\begin{tabular}{lcccc}
\hline & \multicolumn{3}{c}{ Age groups } & \multirow{2}{*}{ Total } \\
\cline { 2 - 4 } & $<\mathbf{2 y}$ & $\mathbf{2 - 1 7 y}$ & $\geq \mathbf{1 8 y}$ & \\
\hline Men & 541 & 4539 & 6860 & 11940 \\
& $4.5 \%$ & $38.0 \%$ & $57.5 \%$ & $100.0 \%$ \\
Women & 532 & 4202 & 6864 & 11598 \\
& $4.6 \%$ & $36.2 \%$ & $59.2 \%$ & $100.0 \%$ \\
All & 1073 & 8741 & $\dagger \mathbf{1 3 7 2 4}$ & 23538 \\
& $4.6 \%$ & $37.1 \%$ & $58.3 \%$ & $100.0 \%$ \\
\hline
\end{tabular}

$\dagger$ - age-group considered eligible $\rightarrow$ randomized for the estimated sample size of 5000

The crude prevalence of CAD was $4.5 \%$ with $95 \%$ CI 3.85 - 5.15. Compared to female $(3.5 \%$, CI, $2.76-4.24)$, the male participants had significantly higher prevalence of CAD $(6.0 \%, \mathrm{CI}, 4.83-7.13)$ [Table 2]. Similarly, compared to people in lower socio-economic class, the higher class had significantly higher prevalence of CAD (p $<0.001)$ [Table-2]. The diabetic participants had significantly higher prevalence $(10.3 \%$ : CI 8.17 12.43) than those with normal or impaired fasting glucose levels $(p<0.001)$ [Table 2]. Similarly, smoking habit $(\mathrm{p}=0.02)$ and metabolic syndrome were significantly $(p<0.05)$ associated with CAD.

The prevalence of CAD showed an increasing trend (Pearson Chi Sq) with increasing quartiles of age $(p=0.004)$, SBP $(p=0.008)$, DBP $(p=0.047)$ and cholesterol $(p=0.016)$ [Figure-2]. It may be noted that quartiles of BMI, WHR, WHtR, TG, LDL and VLDL were also estimated for similar trend but were not found significant (data not shown). 
The characteristics of men and women were compared in Table-3. Though mean (SD) of age, DBP, TG, and VLDL were significantly higher in male than female participants, the obesity related variables (BMI, WHR) and FBG did not differ [Table 3] except WHtR, which was significantly higher in female.

Table-2: Prevalence (\%) of coronary artery disease (CAD) according to sex, social class, glycemic status, smoking habit and metabolic syndrome

\begin{tabular}{|c|c|c|c|}
\hline \multirow{2}{*}{ Variables } & \multirow{2}{*}{$\mathbf{n}$} & CAD & \multirow{2}{*}{$X^{2}, p$} \\
\hline & & $\%(95 \% \mathrm{CI})$ & \\
\hline $\begin{array}{l}\text { Total } \\
\text { participants }\end{array}$ & 3928 & $4.5(3.85-5.15)$ & \\
\hline Men & 1590 & $6.0(4.83-7.17)$ & 14.0, \\
\hline Women & 2338 & $3.5(2.76-4.24)$ & $<0.001$ \\
\hline \multicolumn{4}{|l|}{ Social class } \\
\hline Poor & 724 & $3.6(2.24-4.96)$ & \multirow{3}{*}{$\begin{array}{l}10.4 \\
<0.001\end{array}$} \\
\hline Middle & 2769 & $4.3(3.54-5.06)$ & \\
\hline Rich & 428 & $7.5(5.00-9.99)$ & \\
\hline \multicolumn{4}{|c|}{ Glycemic status (FBG, mmol/l) } \\
\hline $\mathrm{NFG}(\leq 5.5)$ & 3470 & $4.3(5.00-9.99)$ & \multirow{3}{*}{$\begin{array}{l}17.1 \\
<0.001\end{array}$} \\
\hline IFG (5.6-6.9) & 275 & $3.3(5.00-9.99)$ & \\
\hline $\mathrm{DM}(\geq 7.0)$ & 204 & $10.3(5.00-9.99)$ & \\
\hline \multicolumn{4}{|l|}{ Smoking habit } \\
\hline No & 3032 & $4.1(3.39-4.81)$ & 5.1, \\
\hline Yes & 917 & $5.9(4.37-7.43)$ & $p=02$ \\
\hline \multicolumn{4}{|l|}{ MetS* } \\
\hline Absent & 3941 & $4.5(3.85-5.15)$ & 7.8, \\
\hline Present & 8 & $25(-5.00-55.0)$ & $\mathrm{p}<0.05$ \\
\hline
\end{tabular}

* MetS - Metabolic syndrome based on highest quartile of waist-girth $(>80 \mathrm{~cm})$, systolic blood pressure $>130$ $\mathrm{mmHg}$, fasting blood glucose $>5.5 \mathrm{mmol} / \mathrm{l}$ and triglyceride $>130 \mathrm{mg} / \mathrm{dl}$ ). NFG - normal fasting glucose, IFG - impaired fasting glucose, DM - diabetes mellitus

The comparison of quantitative variables were made between participants with and without CAD [Table -4]. Most of the (risk) variables did not differ between them except age $(p<0.001)$, SBP $(p$ $=0.002)$, DBP $(\mathrm{p}=0.001)$ and FBG $(\mathrm{p}=0.003)$. Evidently, none of the obesity related variables
(BMI, WHR, WHtR) differ between CAD and non-CAD nor did the lipids (Chol, Tg, LDL and VLDL). Thus, these findings were found inconsistent and inconclusive. So, these risk variables were quantified by logistic regression.

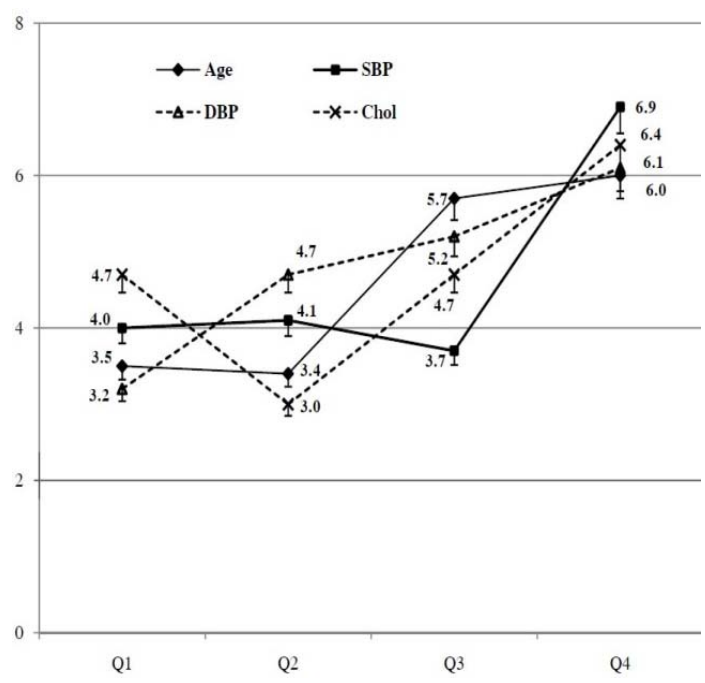

Fig-2: Prevalence of $C A D$ according to quartiles ( $Q 1, Q 2$, Q3, Q4) of age, systolic blood pressure (SBP), diastolic blood pressure (DBP) and total cholesterol (Chol). The trend (Pearson Chi Sq.) for Age ( $p=0.004)$, BPS $(p=0.008)$, $B P D(p=0.047)$ and Chol $(p=0.016)$

Binary logistic regression (forward stepwise) estimated different risk factors as independent and CAD as a dependent variable in four different models (Table-5). In model 1 , we included sex $(\mathrm{f}=1, \mathrm{~m}=2)$, social class (poor $=1$, rich $=2)$, agequartile (Q1 through Q2) and metabolic syndrome $($ no $=1$, yes $=2)$. In model-2, glycemic levels were added to model-1. In subsequent models, the quartiles of SBP (model-3) and chol (model-4) were added. Finally, four risk factors retained their significance (male sex, rich class, diabetes and Q4 of SBP). The odds ratio (with $95 \% \mathrm{CI}$ ) for men was $1.83(\mathrm{CI}, 1.30-2.56)$; the rich class $1.74(\mathrm{CI}$, 1.11 - 2.73); diabetes 1.97 (CI, 1.15 - 3.36) and Q4 of SBP 1.85 (CI, $1.22-2.80)$. The other risk variables (age, metabolic syndrome, chol, TG, HDL, LDL, VLDL) entered stepwise into the logistic equation but these were proved not significant. 
Table-3: Comparison of characteristics between men and women

\begin{tabular}{|c|c|c|c|c|c|c|c|}
\hline \multirow{2}{*}{ Variables } & \multicolumn{3}{|c|}{ Men } & \multicolumn{3}{|c|}{ Women } & \multirow{2}{*}{$\mathbf{p}$} \\
\hline & $\mathbf{N}$ & Mean & SD & $\mathbf{N}$ & Mean & SD & \\
\hline Age (y) & 1590 & 44.6 & 16.2 & 2338 & 40.1 & 15.1 & $<0.001$ \\
\hline Height $(\mathrm{cm})$ & 1523 & 157.0 & 8.6 & 2241 & 155.6 & 8.9 & $<0.001$ \\
\hline Weight (kg) & 1521 & 48.7 & 9.4 & 2238 & 48.3 & 9.4 & 0.038 \\
\hline Waist (cm) & 1498 & 71.4 & 9.3 & 2211 & 71.6 & 9.7 & ns \\
\hline Hip (cm) & 1497 & 84.1 & 7.6 & 2210 & 84.4 & 8.3 & $\mathrm{~ns}$ \\
\hline Body mass index (BMI) & 1518 & 19.7 & 3.3 & 2236 & 19.8 & 3.3 & ns \\
\hline Waist-to-hip ratio (WHR) & 1495 & 0.89 & 0.08 & 2210 & 0.85 & 0.09 & ns \\
\hline Waist-to-height ratio (WHtR) & 1497 & 0.455 & 0.060 & 2209 & 0.461 & 0.063 & 0.008 \\
\hline Systolic BP (mmHg) & 1516 & 71.5 & 11.8 & 2249 & 72.2 & 12.4 & ns \\
\hline Diastolic BP (mmHg) & 1520 & 111.1 & 19.3 & 2253 & 112.5 & 20.7 & 0.040 \\
\hline Fasting blood glucose $(\mathrm{mmol} / \mathrm{l})$ & 1590 & 4.8 & 1.7 & 2338 & 4.8 & 1.3 & ns \\
\hline Triglycerides (mg/dl) & 1330 & 131.1 & 81.3 & 1991 & 121.1 & 61.8 & $<0.001$ \\
\hline Total cholesterol (mg/dl) & 1330 & 145.2 & 43.7 & 1991 & 143.5 & 44.4 & ns \\
\hline $\mathrm{HDL}(\mathrm{mg} / \mathrm{dl})$ & 1331 & 36.7 & 4.0 & 1988 & 36.8 & 4.2 & ns \\
\hline $\mathrm{LDL}(\mathrm{mg} / \mathrm{dl})$ & 1330 & 82.5 & 38.6 & 1988 & 82.6 & 41.9 & ns \\
\hline VLDL (mg/dl) & 1330 & 26.2 & 16.2 & 1991 & 24.2 & 12.3 & $<0.001$ \\
\hline
\end{tabular}

SD - standard deviation, $p$ after unpaired t-test

Table-4: Comparison of characteristics between participants with coronary artery disease (CAD) and without CAD (Non-CAD)

\begin{tabular}{|c|c|c|c|c|c|c|c|}
\hline \multirow{2}{*}{ Variables } & \multicolumn{3}{|c|}{ Non-CAD } & \multicolumn{3}{|c|}{ CAD } & \multirow{2}{*}{$\mathbf{p}$} \\
\hline & $\mathbf{N}$ & Mean & SD & $\mathbf{N}$ & Mean & SD & \\
\hline Age (y) & 3770 & 41.7 & 15.7 & 179 & 46.4 & 16.3 & $<0.001$ \\
\hline Body mass index (BMI) & 3603 & 19.7 & 3.3 & 172 & 19.5 & 3.3 & $\mathrm{~ns}$ \\
\hline Waist-to-hip ratio (WHR) & 3555 & 0.85 & 0.08 & 171 & 0.86 & 0.08 & ns \\
\hline Waist-to-height ratio (WHtR) & 3556 & 0.46 & 0.06 & 171 & 0.45 & 0.06 & ns \\
\hline Systolic BP (mmHg) & 3621 & 111.7 & 20.0 & 173 & 116.5 & 22.4 & .002 \\
\hline Diastolic BP (mmHg) & 3613 & 71.7 & 12.1 & 173 & 74.8 & 12.8 & .001 \\
\hline Fasting blood glucose (mmol/l) & 3770 & 4.79 & 1.43 & 179 & 5.03 & 1.91 & .033 \\
\hline Triglycerides (mg/dl) & 3182 & 125.1 & 70.3 & 157 & 123.9 & 70.4 & $\mathrm{~ns}$ \\
\hline Total cholesterol (mg/dl) & 3182 & 144.1 & 44.3 & 157 & 147.5 & 40.8 & ns \\
\hline $\mathrm{HDL}(\mathrm{mg} / \mathrm{dl})$ & 3181 & 36.8 & 4.2 & 156 & 36.7 & 3.3 & $\mathrm{~ns}$ \\
\hline $\mathrm{LDL}(\mathrm{mg} / \mathrm{dl})$ & 3180 & 82.4 & 40.8 & 156 & 86.2 & 35.9 & ns \\
\hline VLDL (mg/dl) & 3182 & 25.0 & 14.1 & 157 & 24.7 & 14.1 & $\mathrm{~ns}$ \\
\hline
\end{tabular}

$S D$ - standard deviation, $p$ after unpaired t-test 
Table-5: Binary logistic regression taking CAD as a dependent variable

\begin{tabular}{|c|c|c|c|c|c|c|c|c|}
\hline \multirow{2}{*}{$\begin{array}{l}\text { Independent } \\
\text { Variables }\end{array}$} & \multicolumn{2}{|c|}{ Model 1} & \multicolumn{2}{|c|}{ Model 2} & \multicolumn{2}{|c|}{ Model 3} & \multicolumn{2}{|c|}{ Model 4} \\
\hline & OR & $95 \% \mathrm{CI}$ & OR & $95 \% \mathrm{CI}$ & OR & 95\% CI & OR & $95 \% \mathrm{CI}$ \\
\hline Sex: $f=1, m=2$ & 1.63 & $1.20-2.22$ & 1.61 & $1.18-2.19$ & 1.71 & $1.25-2.34$ & 1.83 & $1.30-2.56$ \\
\hline SES: poor $=1$, rich $=2$ & 1.87 & $1.25-2.80$ & 1.88 & $1.25-2.82$ & 1.81 & $1.19-2.76$ & 1.74 & $1.11-2.73$ \\
\hline \multicolumn{9}{|l|}{ Age quartile } \\
\hline $\mathrm{Q} 1(<30 \mathrm{y})$ & 1 & - & 1 & - & 1 & - & 1 & - \\
\hline Q2 (31 - 40y) & 0.96 & $0.60-1.54$ & 0.95 & $0.59-1.52$ & 0.90 & $0.56-1.46$ & 0.91 & $0.55-1.52$ \\
\hline Q3 $(41-52 y)$ & 1.65 & $1.07-2.53$ & 1.62 & $1.05-2.50$ & 1.62 & $1.05-2.50$ & 1.54 & $0.96-2.47$ \\
\hline $\mathrm{Q} 4(>52 \mathrm{y})$ & 1.60 & $1.06-2.42$ & 1.53 & $1.01-2.32$ & 1.42 & $0.93-2.17$ & 1.27 & $0.79-2.02$ \\
\hline MetS: no $=1$, yes $=2$ & 6.78 & $1.33-34.59$ & 4.73 & $0.86-26.00$ & 3.07 & $0.55-17.27$ & 2.35 & $0.41-13.38$ \\
\hline \multicolumn{9}{|l|}{ Glycemia (mmol/l) } \\
\hline NFG & & & 1 & - & 1 & - & 1 & - \\
\hline IFG & & & 0.69 & $0.35-1.38$ & 0.72 & $0.36-1.44$ & 0.74 & $0.37-1.49$ \\
\hline DM & & & 2.08 & $1.25-3.47$ & 2.005 & $1.21-3.47$ & 1.97 & $1.15-3.36$ \\
\hline \multicolumn{9}{|l|}{ SBP Quartiles (mmHg) } \\
\hline $\mathrm{Q} 1(<100)$ & & & & & 1 & - & 1 & - \\
\hline Q2 (100 - 110) & & & & & 0.99 & $0.65-1.51$ & 1.08 & $0.69-1.69$ \\
\hline Q3 (111 - 120) & & & & & 0.87 & $0.52-1.46$ & 0.83 & $0.47-1.47$ \\
\hline $\mathrm{Q} 4(>120)$ & & & & & 1.69 & $1.14-2.49$ & 1.85 & $1.22-2.80$ \\
\hline \multicolumn{9}{|l|}{ TC quartile (mg/dl) } \\
\hline Q1 $(<118)$ & & & & & & & 1 & - \\
\hline Q2 (119 - 139) & & & & & & & 0.59 & $0.35-0.99$ \\
\hline Q3 (140 - 165) & & & & & & & 0.88 & $0.55-1.41$ \\
\hline $\mathrm{Q} 4(>165)$ & & & & & & & 1.21 & $0.78-1.88$ \\
\hline
\end{tabular}

$C I-95 \%$ confidence interval, $f$-female, $m$ - male, FBG-fasting blood glucose, Met $S$ - metabolic syndrome, $N F G$ - normal fasting glucose $\leq 5.5 \mathrm{mmol} / \mathrm{L}, I F G$ - impaired fasting glucose 5.6-6.9 mmol/L, DM - diabetes mellitus $\geq 7.0 \mathrm{mmol} / \mathrm{L}$, OR-odds ratio, SBP - systolic blood pressure, SES - socio-economic status, TC - total cholesterol

\section{Discussion}

This is a population based study and appears to be unique considering its commencement with a census of the study communities that included all possible socio-demographic information. Most of the studies reported the prevalence of CAD and its risk factors separately. Very few studies investigated which risk and how much that is attributable to CAD and why the prevalence and the risks differ across communities, classes and countries [2-5].

This study emphasized not only the prevalence of CAD in a rural population, which comprises almost $70 \%$ [7] of the country, but also included the background information (census) related to known risk factors (family income, education, occupation, smoking, family history). Other known risks (obesity, blood pressure, glycemia, lipids) were also investigated. Additionally, we quantified each specific risk whether or not contributing for developing CAD.
The CAD prevalence of this study $(4.5 \%$ with $95 \%$ CI $3.85-5.15 ; \mathrm{m} / \mathrm{f}=6.0 / 3.9 \%$ ) is lower than urban population of Rajasthan $(\mathrm{m} / \mathrm{f}=6.18$ $/ 10.12 \%$ ) [9] and Jaipur ( $\mathrm{m} / \mathrm{f}=9.2 / 11.7 \%$ ) [10]; but consistent with findings of Scotland study $(\mathrm{m} / \mathrm{f}=5.5 / 3.9 \%)$ [11]. Again, the study findings are inconsistent regarding the proportion of CAD in male and female groups. The urban female population had more CAD than males [9, 10]; whereas, our finding and Scotland study [11] had male preponderance.

The known modifiable risks of CAD are obesity, dyslipidemia, smoking, hyperglycemia and hypertension; and the non-modifiable major risks are age and inheritance [2-4]. But these are not unequivocally proven risks as reported by others. For example, though obesity is thought to be an important risk, obesity reduced $\mathrm{CAD}$ as reported by Tsujimoto $T$ [5] and De Shutter [6]. It is interesting that some studies have observed high CAD mortality among people with low body fat 
and /or low lean mass index; and low mortality among the obese individuals $[12,15,16]$. Higher BMI, WHR and WHtR in this study showed no significant association with CAD. Logistic regression analyses proved obesity had neither excess nor reduced risk for CAD. Likewise, dyslipidemia (high chol, Tg, LDL, VLDL and low HDL) were known risk for CAD [13,14]. On the contrary, our study findings did not show excess risk of dyslipidemia for CAD.

The prevalence of CAD increases with increasing age due to metabolic derangement attributed to in ageing process (hyperglycemia, dyslipidemia, atherogenesis, hypertension). The findings of this study did not show such effect of advancing age on CAD. This means that even younger people bear the risk of CAD. This particular finding is consistent with the study addressing 'overweight risk paradox in aging' [15].

Some other risk variables were expected to contribute to CAD, but eventually, proved not significant as CAD risk. Family history of diabetes, hypertension, CAD and stroke was found not significant. Metabolic syndrome was also thought to be an important CAD risk. Bivariate quantitative analysis showed that the participants with MetS had almost six-fold higher CAD than those without MetS (Table-2: $25.0 \%$ vs $4.5 \%$ ). But, logistic regression analysis disproved its effect on CAD. MetS though associated with CAD, it has not been found consistent $[17,18]$. Smoking was found significant (Table-2: $p=0.02$ ) in bivariate analysis, but ultimately was found insignificant.

The study, however, unequivocally proved that the male participants, higher social class, higher systolic blood pressure and hyperglycemia (FBG $>7.0 \mathrm{mmol} / \mathrm{L}$ ) had independent risk of CAD. These findings are very much consistent with other studies [2-4].

However, there are some issues remained unexplained. If not obesity and dyslipidemia are CAD risk, then what other risk factors are related to CAD? Why the younger people had similar $\mathrm{CAD}$ risk as the aged?

We could not investigate some simple but important risks like physical activity and diet. This is the shortfall of this study. Additionally, it would have been better if we could include C-reactive protein [19,20], Vitamin D [21] and homocysteine level [22], which are considered CAD risk, directly or indirectly. Though not very evident, it is also important to explore whether genetic predisposition have any contribution to CAD $[23,24]$.

\section{Conclusion}

We may conclude that the prevalence of CAD in rural Bangladeshi people is not insignificant and is comparable to other developed countries. The male sex, rich social class, hypertension and diabetes were independent risk for CAD. Obesity and dyslipidemia had no effect on CAD. Younger people had equal CAD risk as the aged people. Thus it becomes imperative to initiate primordial and primary prevention. It is also suggested that further study may be undertaken to determine the role of physical activity and diet, and if possible, $\mathrm{C}$ reactive protein, Vitamin $\mathrm{D}$ and homocysteine level in CAD.

\section{Acknowledgments}

We are grateful to Ministry of Science and Technology, Government of the People's Republic of Bangladesh, for funding the project. We are also grateful to the Department of Cardiology, Bangabandhu Sheikh Mujib Medical University for their active co-operation in making the necessary investigations for confirmation of diagnosis. We are indebted to the Department of Community Medicine, Ibrahim Medical College for taking the brunt of all biochemical tests. We appreciate the help extended by the Principal, Ibrahim Medical College, who kindly allowed his teaching and technical staff to carry out the study from starting to the end. Finally, we acknowledge the contributions made by the principals, headmasters, teachers and students of the educational institutes; and local leaders and the participants of the study sites, who actively volunteered.

\section{References}

1. World Health Organization, Projections of mortality and burden of disease, 2002-2030. http://www.who.int/healthinfo/global_burden _disease/projections/en/index.html. 
2. Marzona I, Avanzini F, Lucisano G, Tettamanti M, Baviera M, Nicolucci A, Roncaglioni MC. Risk \& prevention collaborative group. Are all people with diabetes and cardiovascular risk factors or microvascular complications at very high risk? Findings from the rsk and prevention study. Acta Diabetol. 2017; 54(2): 123-131.

3. Patel SA, Ali MK, Alam D, Yan LL, Levitt NS, Bernabe-Ortiz A, Checkley W, et al. Obesity and its relation with diabetes and hypertension: a cross-sectional study across 4 geographical regions. Glob Heart. 2016; 11(1): 71-79.e4.

4. Mohebi R, Bozorgmanesh M, Azizi F, Hadaegh F. Effects of obesity on the impact of short-term changes in anthropometric measurements on coronary heart disease in women. Mayo Clin Proc. 2013; 88(5): 487-94.

5. Tsujimoto T, Kajio H, Sugiyama T. Risks for cardiovascular and cardiac deaths in non-obese patients with diabetes and coronary heart disease. Mayo Clin Proc. 2016; 91(11): 15451554.

6. De Schutter A, Lavie CJ, Patel DA, Milani RV. Obesity paradox and the heart: which indicator of obesity best describes this complex relationship? Curr Opin Clin Nutr Metab Care. 2013; 16(5): 517-24.

7. Rahman MN, Kamal GM. Statistical pocket book of Bangladesh 2013. Dhaka, Bureau of Statistics, Statistical Division, Ministry of Planning, Government of Peoples Republic of Bangladesh, 2013.

8. Tziomalos K, Weerasinghe CN, Mikhailidis DP, Seifalian AM. Vascular risk factors in South Asians. Int J Cardiol. 2008; 128(1): 5-16.

9. Gupta R, Prakash H, Majumdar S, Sharma S, Gupta VP. Prevalence of coronary heart disease and coronary risk factors in an urban population of Rajasthan. Indian Heart J. 1995; 47(4): 331-8.

10. Gupta R, Gupta VP, Sarna M, Bhatnagar S, Thanvi J, Sharma V, Singh AK, Gupta JB, Kaul V. Prevalence of coronary heart disease and risk factors in an urban Indian population: Jaipur Heart Watch-2. Indian Heart J. 2002; 54(1): 59-66.
11. Smith WC, Kenicer MB, Tunstall-Pedoe H, Clark EC, Clark EC, Crombie IK Prevalence of coronary heart disease in Scotland: Scottish heart health study. Br Heart J. 1990; 64(5): 295-8.

12. Lavie CJ, De Schutter A, Patel DA, RomeroCorral A, Artham SM, Milani RV. Body composition and survival in stable coronary heart disease: impact of lean mass index and body fat in the "obesity paradox". J Am Coll Cardiol. 2012; 60(15): 1374-80.

13. Alexander CM, Landsman PB, Teutsch SM, Haffner SM. Third national health and nutrition examination survey (NHANES III); national cholesterol education program (NCEP). NCEP- defined metabolic syndrome, diabetes and prevalence of coronary heart disease among NHANES III participants age 50 years and older. Diabetes. 2003; 52(5): 1210-4.

14. Acevedo $M$, Valentino $G$, Kramer V, Bustamante MJ, Adasme M, Orellana L, Baraona F, Navarrete C. Evaluation the American College of Cardiology and American Heart Association Predictive score for cardiovascular diseases. Rev Med Chil. 2017; 145(3): 292-298.

15. Bowman K, Atkins JL, Delgado J, Kos K, Kuchel GA, Ble A, Ferrucci L, Melzer D. Central adiposity and the overweight risk paradox in aging: follow-up of 130,473 UK biobank participants. Am J Clin Nutr. 2017; pii: ajen147157. doi: 10.3945/ajen.116. 147157.

16. Sharma S, Batsis JA, Coutinho T, Somers VK, Hodge DO, Carter RE, et al. Normalweight central obesity and mortality risk in older adults with coronary artery disease. Mayo Clin Proc. 2016; 91(3): 343-51.

17. Timóteo AT, Mota Carmo M, Cruz Ferreira R. Does metabolic syndrome predict significant angiographic coronary artery disease? Rev Port Cardiol. 2012; 31(12): 769-78.

18. Yoon SE, Ahn SG, Kim JY, Park JS, Shin JH, Tahk SJ, et al. Differential relationship between metabolic syndrome score and severity of coronary atherosclerosis as assessed by angiography in a non-diabetic and diabetic 
Korean population. J Korean Med Sci. 2011; 26(7): 900-5.

19. Gul C, Marwat ZI, Israr M, Hanif R, Arshad M. C-reactive protein level in coronary artery disease and its correlation with serum Ddimer. J Ayub Med Coll Abbottabad. 2016; 28(4): 725-729.

20. Radetti G, Grugni G, Lupi F, Marazzi N, Longhi S, Fanolla A, Sartorio A. The relationship between hyperthyrotropinemia and metabolic and cardiovascular risk factors in a large group of overweight and obese children and adolescents. J Endocrinol Invest. 2017; doi: 10.1007/s40618-017-0705-z.

21. Separham A, Sohrabi B, Pourafkari L, Sepasi N, Ghaffari S, Aslanabadi N, Nader ND. Vitamin D is a predictor of ST segment resolution and infarct size following thrombolysis in patients with acute ST elevation myocardial infarction. Turk Kardiyol Dern Ars. 2017; 45(4): 324-332.
22. Blum A, Lupovitch S, Khazim K, Peleg A, Gumanovsky M, Yeganeh S, Jawabreh S. Homocysteine levels in patients with risk factors for atherosclerosis. Clin Cardiol. 2001; 24(6): 463-6.

23. Fernández-Sanlés A, Sayols-Baixeras S, Subirana I, Degano IR, Elosua R. Association between DNA methylation and coronary heart disease or other atherosclerotic events: A systematic review. Atherosclerosis. 2017; pii: S0021-9150(17) 30225-3. doi: 10.1016/j. atherosclerosis.2017.05.022.

24. Zewinger S, Kleber ME, Tragante V, McCubrey RO, Schmidt AF, Direk K, Laufs U, Werner C, et al. Relations between lipoprotein(a) concentrations, LPA genetic variants, and the risk of mortality in patients with established coronary heart disease: a molecular and genetic association study. Lancet Diabetes Endocrinol. 2017; 5(7): 534-543. 